\title{
BMJ Open Health economic assessment of a scenario to promote bicycling as active transport in Stockholm, Sweden
}

\author{
Hedi Katre Kriit, ${ }^{1}$ Jennifer Stewart Williams, ${ }^{2}$ Lars Lindholm, ${ }^{2}$ Bertil Forsberg, ${ }^{1}$ \\ Johan Nilsson Sommar ${ }^{\circ}$
}

To cite: Kriit HK, Williams JS, Lindholm L, et al. Health economic assessment of a scenario to promote bicycling as active transport in Stockholm, Sweden. BMJ Open 2019;9:e030466. doi:10.1136/ bmjopen-2019-030466

- Prepublication history for this paper is available online. To view these files, please visit the journal online (http://dx.doi. org/10.1136/bmjopen-2019030466).

Received 15 March 2019 Revised 06 August 2019 Accepted 14 August 2019

Check for updates

(C) Author(s) (or their employer(s)) 2019. Re-use permitted under CC BY. Published by BMJ.

${ }^{1}$ Sustainable Health, Department of Public Health and Clinical Medicine, Umeå University, Umeå, Sweden

${ }^{2}$ Department of Epidemiology and Global Health, Umeå University, Umeå, Sweden

Correspondence to

Hedi Katre Kriit;

hedi.kriit@umu.se

\section{ABSTRACT}

Objectives To conduct a health economic evaluation of a proposed investment in urban bicycle infrastructure in Stockholm County, Sweden.

Design A cost-effectiveness analysis is undertaken from a healthcare perspective. Investment costs over a 50year life cycle are offset by averted healthcare costs and compared with estimated long-term impacts on morbidity, quantified in disability-adjusted life years (DALYs). The results are re-calculated under different assumptions to model the effects of uncertainty.

Setting The Municipality of Stockholm (population 2.27 million) committed funds for bicycle path infrastructure with the aim of achieving a $15 \%$ increase in the number of bicycle commuters by 2030 . This work is based on a previously constructed scenario, in which individual registry data on home and work address and a transport model allocation to different modes of transport identified 111487 individuals with the physical capacity to bicycle to work within 30 min but that currently drive a car to work. Results Morbidity impacts and healthcare costs attributed to increased physical activity, change in air pollution exposure and accident risk are quantified under the scenario. The largest reduction in healthcare costs is attributed to increased physical activity and the second largest to reduced air pollution exposure among the population of Greater Stockholm. The expected net benefit from the investment is $8.7 \%$ of the 2017 Stockholm County healthcare budget, and $3.7 \%$ after discounting. The economic evaluation estimates that the intervention is cost-effective and each DALY averted gives a surplus of $€ 9933$. The results remained robust under varied assumptions pertaining to reduced numbers of additional bicycle commuters.

Conclusion Investing in urban infrastructure to increase bicycling as active transport is cost-effective from a healthcare sector perspective.

\section{BACKGROUND}

Four chronic illnesses-cardiovascular disease, cancer, type 2 diabetes and respiratory disorders-account for at least $60 \%$ of global deaths. Several known modifiable lifestyle behaviours, such as tobacco smoking, unhealthy diets, harmful alcohol use and physical inactivity, impact on these chronic illnesses through associations with

\section{Strengths and limitations of this study}

This transport mode shift scenario is based on registry data and reflects potential outcomes from increased bicycling in Stockholm County.

- Due to data limitations, it was not possible to model possible changes in population health in the absence of the intervention.

- Investment costs are compared with the expected reduction of chronic disease-related healthcare costs due to the transport mode shift.

- Secondary data were used to estimate the lifetime costs of chronic diseases.

risk factors, such as obesity, hypertension and high blood sugar levels. ${ }^{1-6}$ Physical inactivity is the fourth most important risk factor for premature mortality in the European Union after tobacco smoking, high blood pressure and overweight. ${ }^{5}$

There is now widespread evidence of the importance of physical activity in promoting and maintaining good health. ${ }^{356}$ Even the relatively inactive can benefit from marginal increases in physical activity. ${ }^{7}$ Since 2010 , when the first official set of global recommendations for physical activity were launched by the World Health Organization (WHO), ${ }^{3}$ policies to address insufficient physical activity have been implemented in over half WHO Member States. ${ }^{6}$

Currently, half of the world's population live in urban environments and this proportion is expected to reach $60 \%$ by $2030 .^{89}$ Participation in physical activity can be difficult in cities where the heavy use of motorised transportation is estimated to be responsible for $70 \%$ of environmental urban air pollution and $13 \%$ of global green gas emissions. ${ }^{10}$ In 2010 , road transport contributed $40 \%$ of the economic costs of premature deaths from air pollution in the WHO European Region. ${ }^{11}$

Active transport through, for example, bicycling as a way of commuting to work has 
been suggested as a way of increasing physical activity and reducing motorised traffic emissions in urban areas. However, the health gains for those switching from car to bike transport in heavy traffic areas are offset by the increased risk of serious injury and greater exposure to poor air quality. Furthermore, the distribution of costs and benefits is not equally spread across socioeconomic and demographic groups. ${ }^{7213}$

In a study of the cost-effectiveness of interventions to encourage more physical activity in the Australian population, Cobiac et al reported that a package of physical activity interventions that include active transport could yield both public health benefits and health sector cost savings. ${ }^{14}$ Another study in Australia estimated that healthcare costs would be reduced by $\$ A 1.12$ per bicycled kilometre. ${ }^{15}$ Studies using previously published disease-specific healthcare costs have estimated significant cost reductions based on hypothetical scenarios of increased active commuting in the $\mathrm{UK}^{16}$ and Italy. ${ }^{17}$ For example, Jarret et al estimated that the National Health Service could save roughly $£ 17$ billion within 20 years due to reduced prevalence of seven non-communicable diseases (NCDs) resulting from increased walking and bicycling. ${ }^{16}$ A number of economic assessments have suggested that travel-related/transport-related interventions are cost-effective in terms of costs per healthy life-year gained in adult populations. ${ }^{78}$ Although, not without methodological challenges, there is a need to evaluate the costs and benefits of interventions that promote physical activity through active transport from a health sector perspective. ${ }^{19} 20$

In 2015, NCDs accounted for $€ 115$ billion in healthcare costs in European countries. ${ }^{21}$ Strategies that address physical inactivity can deliver public health gains through the prevention of chronic diseases. Active transport strategies involving a shift from motor transport can also have wider benefits for the population through improvements in air quality. Sound economic evaluations are needed to build an evidence base in this area. ${ }^{2}$

This paper presents a health economic evaluation of a proposed investment in urban bicycle infrastructure in Stockholm, Sweden, from a healthcare sector perspective. The long-term change in outcomes and healthcare costs are quantified within a scenario of increased commuting by bicycle and cost-effectiveness is derived in relation to the planned investment.

\section{METHODS}

\section{Evaluation scenario}

As part of its 2018-2030 plan, the Municipality of Stockholm (population 2.27 million) committed funds for bicycle path infrastructure with the aim of achieving a 15\% increase in bicycle commuters by 2030. Based on the previously developed transport shift scenario, it is estimated that 111487 current car drivers could potentially switch to bicycle commuting between home and work. Thereafter, in the economic evaluation, it is assumed that yearly investment costs lead to a proportional amount of new bicyclists from the estimated number of potential converters. Health impacts, attributed to increased physical activity, differential exposure to air pollution and traffic accidents, and changes in healthcare costs are evaluated for potential bicycle commuters, current bicycle commuters and the general population. The timeline assumes that it takes 12 years of investment for all estimated potential bicyclists to shift their mode of transport and health impacts are calculated for a 50-year life length of the investment in bicycle path infrastructure.$^{22}$ Yearly health impacts are compared, ceteris paribus, with current 2017 register data on disease incidences that were assumed to be constant during the 50 years of assessment. The corresponding estimated lifetime healthcare costs were calculated and used as a comparator for cost-effectiveness analysis.

\section{Population base}

The study population is based on a scenario constructed for a previous study in which data on geolocation, demography and commuting modes by origin and destination zone were referenced ${ }^{22}$ Home and workplace addresses were retrieved from the ASTRID database, which has been collecting individual-level data on the Swedish population for over 50 years. ${ }^{23}$ Using the LuTrans transport model, ${ }^{24}$ each individual within ASTRID was allocated to different modes of commuting based on travel survey information and registry data on car ownership. Regression functions were used to model the probability for each mode of travel between small statistical areas of Stockholm County. A total of 111487 individuals from the Stockholm County population register who currently drive a car to work were identified as potential bicycle commuters based on geographic distance from home to work and expected bicycle speed based on age and sex. Eligibility required an estimated bicycle commute of 30 min or less each way. ${ }^{22} 25$

\section{Estimating health outcomes}

Sommar et $a l^{26}$ estimated changes in morbidity and mortality associated with the above chronic diseases and traffic accidents under the scenario, for potential bicycle commuters, current bicycle commuters and the general population. First, estimated health impacts due to increased physical activity among potential bicycle commuters were quantified in terms of decreased risk of type 2 diabetes, myocardial infarction (MI), stroke, dementia, colon cancer, breast cancer and heart failure. Second, change in air pollution exposure is assumed to benefit current bicycle commuters and the general population and disadvantage additional bicycle commuters in terms of risk for asthma, lung cancer, type 2 diabetes, stroke and MI. ${ }^{26}$ Third, health effects of injuries attributable to traffic accidents under this scenario of 111 487 potential bicycle commuters are also estimated. ${ }^{27}$ Estimated disability-adjusted life years (DALYs) were calculated for each area of health impact based on the disability weights reported by the WHO Global Burden 
of Disease 2004 updates and expected changes in disease incidence. The duration of the disease was calculated as the expected life length after the first disease incidence. Life table calculations using mortality data for Stockholm County were used to calculate expected remaining life years based on age and gender. ${ }^{26}$

\section{Estimating cost-effectiveness}

Information on the budget allocation for the bicycle pathways was obtained from the Stockholm Traffic Planning Office. ${ }^{22}{ }^{28}$ The expected life cycle for new bicycle paths constructed in 2018 is 50 years. ${ }^{29}$

The investment period of 2018-2030 was used as a build-up time to reach the estimated amount of additional bicyclists. We estimate that yearly investment costs will vary due to political and other circumstances. The number of additional bicyclists estimated to start active commuting in a given year is a proportion of the estimated potential bicycle commuters, based on that year's investment allocation (approximately $€ 15$ million per year). Health impacts were simultaneously estimated consistent with the proportion of additional bicyclists in a given year. After 2030, an estimated 111487 additional bicyclists were expected to commute. The number of DALYs attributable to this transport mode change was modelled for the remaining years. Long-term healthcare costs (added and averted) are estimated in accordance with the change in health outcomes attributed to: (1) increased physical activity by potential bicycle commuters; (2) air pollution change for potential bicycle commuters; (3) air pollution change for current bicycle commuters; (4) air pollution change for the general population and (5) traffic accidents incurred by potential bicycle commuters. These costs are given both in absolute terms and as the proportion of the 2017 Stockholm Municipality health budget. ${ }^{30}$

Health outcomes are calculated for the 50 -year period, 2018-2068, taking the time interval between exposure and realised health benefits into account. It is estimated for physical activity exposure that it takes 2 years for $50 \%$ of the health benefits and 6 years for $100 \%$ of the health benefits to be realised for both MI and stroke, ${ }^{31}$ 17 and 20 years, respectively, for $50 \%$ and $100 \%$ of the health benefits to be realised for dementia, breast and colon cancer, ${ }^{31}$ and 3.2 and 8 years, respectively, for $50 \%$ and $100 \%$ of the health benefits to be realised for type 2 diabetes. ${ }^{32}$ The impacts of air pollution and traffic injuries were both assumed to occur during the current year. The mode shift from car to bicycle was assumed to be the only change in the exposure.

This cost-effectiveness analysis adopts the Consolidated Health Economic Evaluation Reporting Standards (CHEERS) guidelines for health economic modelling. ${ }^{33}$ Costs are reported in euros (2017). Figure 1 shows the steps undertaken. The cost-effectiveness assumed that healthcare costs would be reinvested yearly, and therefore discounting was not used. Costs are, however, also reported with a $3 \%$ discount rate.

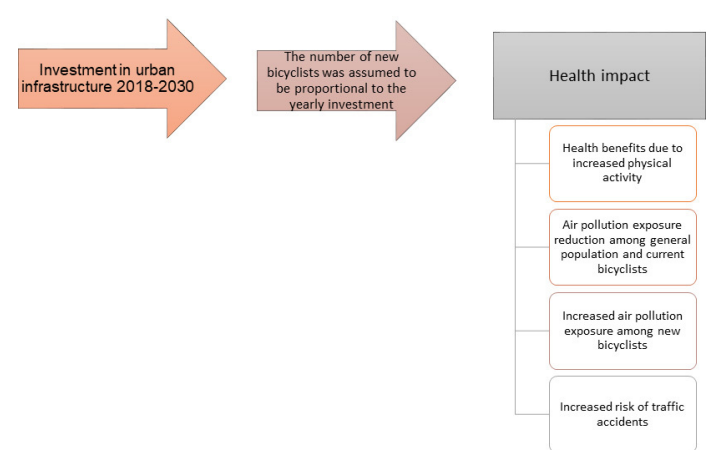

Figure 1 Flow chart for estimated chain of events as the base for conducting the cost-effectiveness analysis.

\section{Sensitivity analyses}

Sensitivity analysis is undertaken for the same investment costs assuming that numbers of potential bicycle commuters are as few as $25 \%$ of the estimated potential bicyclists. In addition, the sensitivity to a reduced health impact and healthcare cost is provided. Results were reported in terms of its effect on the cost-effectiveness ratio (CER).

\section{Estimating long-term healthcare costs}

The literature was used to inform estimates of longterm healthcare costs for type 2 diabetes, MI, stroke, heart failure, dementia, colon cancer, breast cancer, lung cancer and asthma (table 1). For comparability with Sweden, only papers reporting studies in high-income countries, in which healthcare costs were met by public funds, were sought. Inclusion required that study estimates were based on administrative data recording healthcare costs matched to clinical diagnoses. The search was conducted in Google Scholar, PubMed and Web of Science between 1995 and 2018. Search terms included the health condition of interest and lifetime/ long-term costs. As no studies were found that specifically reported lifetime healthcare costs for asthma, MI or cancer outcomes, these estimates are based on 1-year average healthcare costs for asthma, 6-year average for MI and 5-year disease costs for cancer.

Estimates of the costs for bicycle-related injuries were derived from a study conducted in the Netherlands, which used national registry and hospital data covering the period 1998-2012. ${ }^{34}$ Reported average cost per injury was $€ 2765$.

\section{RESULTS}

\section{Investment cost}

The net infrastructure cost, excluding communication and maintenance costs, is $€ 101$ million. Assuming a 50-year life cycle for the bicycle path, a $€ 2$ million annual investment gives an average annual cost of $€ 908$ per converter.

\section{Changes in healthcare costs}

The expected healthcare costs assuming the current burden of included diseases during the 50-year life span 


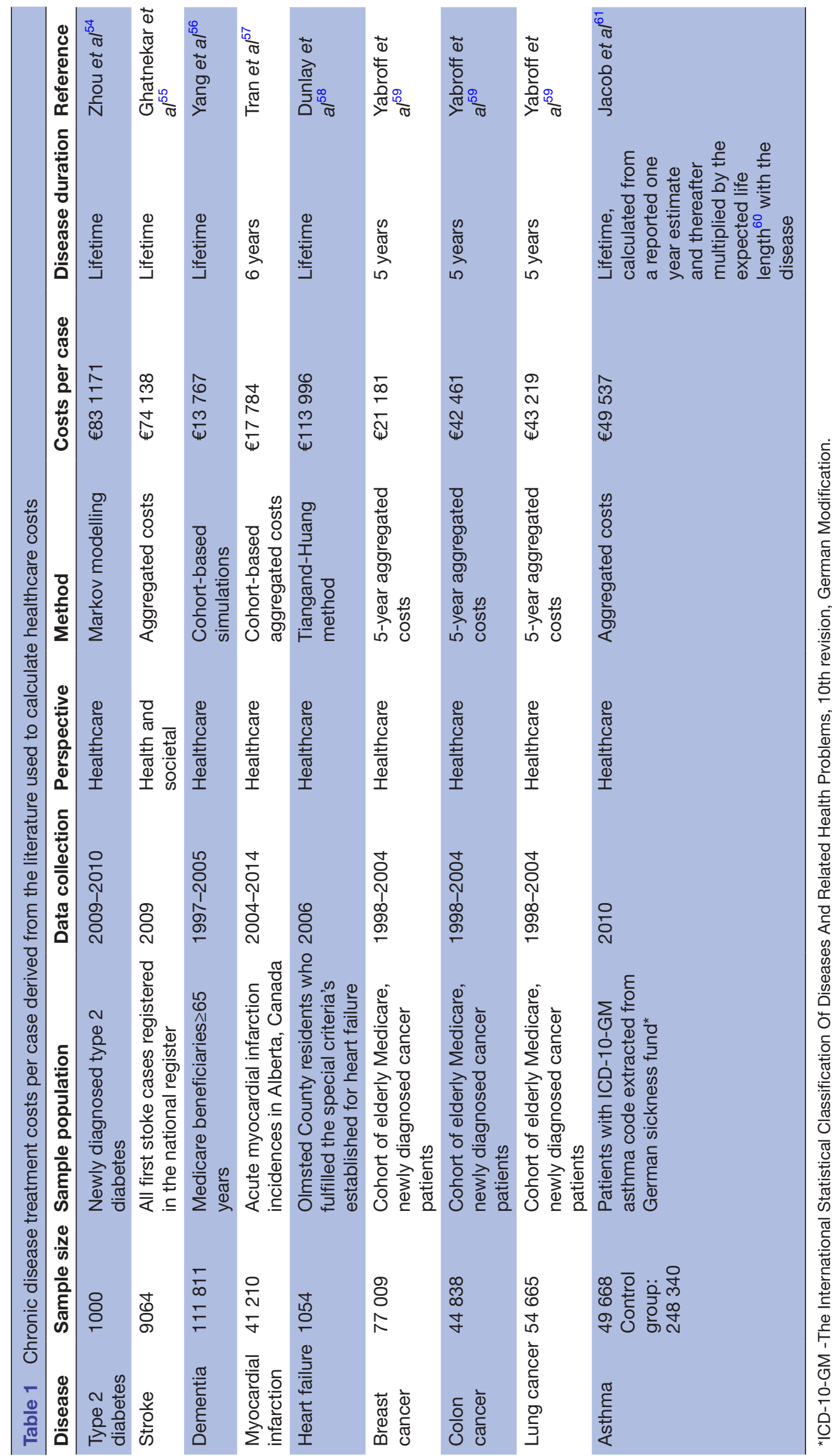

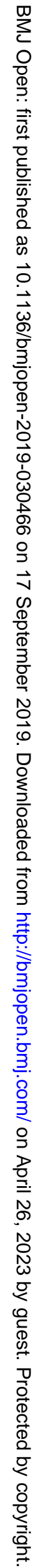


Table 2 Estimated healthcare costs assuming the 2017 disease burden, changed disease burden as a result of increased bicycling, and estimated difference in healthcare costs

\begin{tabular}{|c|c|c|c|c|c|}
\hline Exposure & $\begin{array}{l}\text { Healthcare costs } \\
\text { with the current } \\
\text { burden of disease }\end{array}$ & $\begin{array}{l}\text { Healthcare costs in } \\
\text { the scenario }\end{array}$ & $\begin{array}{l}\text { Estimated change in } \\
\text { healthcare costs in } \\
\text { the scenario }\end{array}$ & $\begin{array}{l}\text { Percentual } \\
\text { reduction in } \\
\text { healthcare costs }\end{array}$ & $\begin{array}{l}\text { change } \\
\text { in DALYs } \\
\text { in the } \\
\text { scenario }\end{array}$ \\
\hline Physical activity & $€ 2073803338$ & $€ 1511162940$ & $€ 562640398$ & 27.13 & 35060 \\
\hline $\begin{array}{l}\text { Air pollution change } \\
\text { among the general } \\
\text { population }\end{array}$ & $€ 46283254008$ & $€ 46228719501$ & $€ 54534507$ & 0.12 & 21975 \\
\hline $\begin{array}{l}\text { Air pollution change } \\
\text { among additional } \\
\text { bicyclist }\end{array}$ & $€ 1885540341$ & $€ 1899564512$ & $€-14024171$ & -0.74 & -7287 \\
\hline $\begin{array}{l}\text { Air pollution change } \\
\text { among current } \\
\text { bicyclists }\end{array}$ & $€ 874825533$ & $€ 874566906$ & $€ 258627$ & 0.03 & 131 \\
\hline Traffic injuries ${ }^{*}$ & & & $€-88244441$ & & -8210 \\
\hline Total & $€ 46283254008$ & $€ 45768089088$ & $€ 515164920$ & 1.01 & 41669 \\
\hline
\end{tabular}

${ }^{*}$ Current costs related to traffic accidents were not available.

DALYs, disability-adjusted life years.

of the investment was $€ 46$ billion (table 2 ), and $€ 24$ billion after discounting (table 3 ).

The fall in chronic disease cases attributable to increased physical activity among additional bicycle commuters is estimated to save $€ 562$ million, or $€ 241$ million after discounting (3\%), giving an average annual return of $€ 11.24$ million (figure 2).

Traffic generated air pollutants were measured in particle mass concentrations. ${ }^{35}$ Lower healthcare costs attributed to decreased air pollution exposure among current bicycle commuters and the general population are estimated to save $€ 1.2$ million annually. This is offset by increased healthcare costs of $€ 0.28$ million for additional bicycle commuters who are estimated to experience increased exposure to air pollution (figure 2).
The annual additional healthcare costs for injuries sustained as a result of the increased accident risk among additional bicycle commuters is estimated at $€ 1.96$ million.

During the life span of the investment, the estimated total healthcare costs for the included diseases was reduced by $1.1 \%$. This corresponds to $8.7 \%$ of the healthcare expenditure that the Stockholm Council planned for the year 2017, or $3.7 \%$ after discounting.

\section{Costs and benefits}

Costs for the given scenario are compared with no assumed change in bicycle commuting. For each area of impact, the estimated change in healthcare costs and DALYs were calculated (table 2). CER is calculated by

Table 3 Discounted costs assuming the 2017 disease burden, changed disease burden as a result of increased bicycling, and estimated difference in healthcare costs

\begin{tabular}{llll} 
Exposure & $\begin{array}{l}\text { Healthcare costs with } \\
\text { current burden of disease }\end{array}$ & $\begin{array}{l}\text { Estimated change in } \\
\text { healthcare costs in the } \\
\text { scenario }\end{array}$ & $\begin{array}{l}\text { Percentual reduction in } \\
\text { healthcare costs }\end{array}$ \\
\hline $\begin{array}{l}\text { Physical activity } \\
\begin{array}{l}\text { Air pollution change among } \\
\text { the general population }\end{array}\end{array}$ & $€ 24257656022$ & $€ 241629107$ & 22.12 \\
$\begin{array}{l}\text { Air pollution change among } \\
\text { additional bicyclist }\end{array}$ & $€ 988236242$ & $€ 25962558$ & 0.11 \\
$\begin{array}{l}\text { Air pollution change among } \\
\text { current bicyclists }\end{array}$ & $€ 458507452$ & $€-6687730$ & -0.68 \\
$\begin{array}{l}\text { Traffic injuries* } \\
\text { Total }\end{array}$ & $€ 24257656022$ & $€ 108504$ & 0.02 \\
\hline
\end{tabular}

${ }^{*}$ Current burden costs related to traffic accidents were not available. 

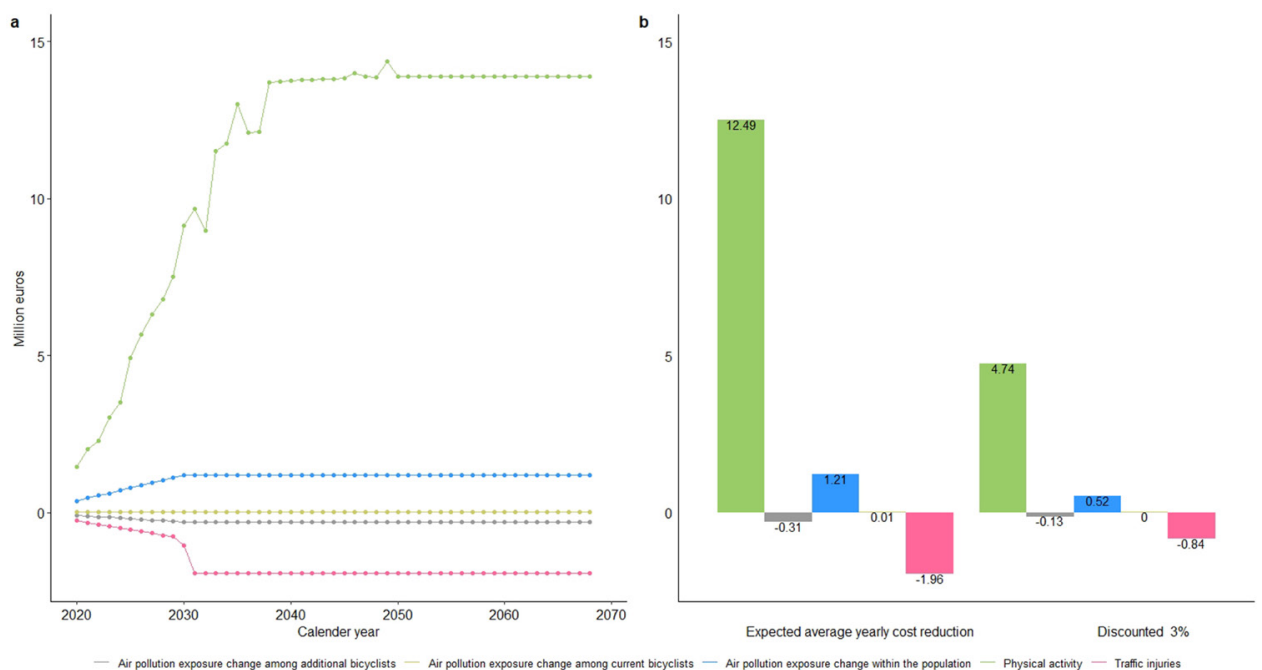

Figure 2 Estimated yearly expenditure averted (in millions) in the healthcare sector due to increased physical activity, change in air pollution concentrations and risk of traffic injuries.

subtracting investment costs from the total estimated healthcare savings and dividing by the estimated reduction of DALYs. Based on our estimates, the investment is cost-effective, averting one DALY gives a surplus of $€ 9933$.

\section{Sensitivity analysis}

The scenario identified 111487 additional bicycle commuters. The sensitivity of the estimates was assessed by assuming fewer potential bicycle commuters. If only $25 \%$ of the 111487 potential bicycle commuters were to change their mode of transport, the CER would still result in a surplus of $€ 2643 /$ DALY averted (figure 3). Even under the assumptions of a reduced health impact and lower expected reductions in healthcare costs, the investment remains highly cost-effective.

\section{DISCUSSION}

This is the first health economic evaluation of this type to use an evidence-based scenario that includes information on geolocation, demography and commuting modes by origin and destination zone drawn from a

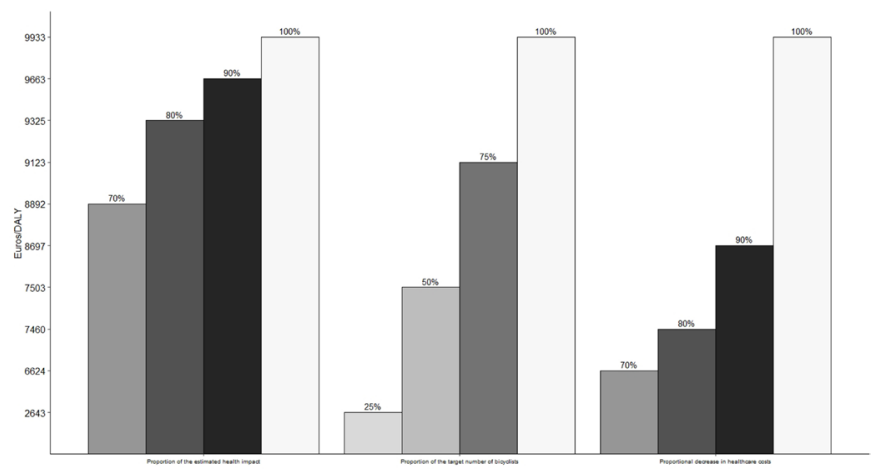

Figure 3 Sensitivity analysis of the CER considering number of obtained bicyclists, health impact and healthcare costs. CER, cost-effectiveness ratio; DALY, disability-adjusted life year. population register. Investment costs were compared with estimated long-term healthcare costs and savings attributed to increased physical activity, change in air pollution exposure and accident risk. To the best of our knowledge, this is also the first economic evaluation to include morbidity health impacts in all three areas of impact. The investment is cost-effective from a healthcare sector perspective.

\section{Physical activity}

The largest reduction in healthcare costs is attributed to increased physical activity. Previous health economic assessments using hypothetical scenarios in Europe have also demonstrated cost savings in the healthcare sector attributed to physical activity. ${ }^{16}{ }^{17}$ In the USA, Grabow et $a l^{36}$ showed that in a population of 2 million across 11 metropolitan areas, if one-half of the commutes, of less than $8 \mathrm{~km}$ round trip, were made by bicycle instead of car, mortality would be reduced by 700 premature deaths. Based on the US statistical value of life, this is equivalent to US $\$ 3.8$ billion (2010 values) annually or US $\$ 1900$ per individual. ${ }^{36}$ In our study, the estimated cost saving attributed to reduced morbidity from increased physical activity is $€ 562$ million or $€ 100$ per annum per additional bicycle commuter.

The benefits from different types of physical activity are variable and not necessarily linear. In their systematic review and meta-analysis of 22 cohort studies including over 977000 people, Woodcock et $a l^{37}$ concluded that, compared with no activity, 2.5 hours per week of moderate-intensity activity was associated with a $19 \%$ reduction in mortality risk and 7 hours per week of moderate activity reduced mortality risk by $24 \%$. In this study, physical activity effects are reported only for bicycling although adjustments were made for other likely types of physical activity based on individuals' assumed physical capacity adjusted for age and sex. 


\section{Air pollution}

Some other health economic analyses have assessed the economic value of a reduction in morbidity and mortality due to a reduction in air pollution exposure. Lindsay et $a l l^{38}$ for example, estimated the effect of reduced air pollution exposure on mortality, numbers of active days, and acute cardiac and respiratory hospital admissions by calculating cost per health event and the statistical value of life based on New Zealand willingness to pay studies. Grabow et $a l^{36}$ used a BenMAP cost-benefit regulatory analysis to address the potential benefits attributable to an air pollution reduction in the general population as a result of a transport mode change from car to bicycle for trips of $8 \mathrm{~km}$ or less in various US cities. Based on acute hospital costs attributable to reduced automobile exhaust and increased ozone exposure, net benefits were estimated at US $\$ 4.94$ billion (2010 values).

To the best of our knowledge, this economic evaluation is also the first to model the impact of a change in air pollution exposure within the general population as well as among current bicycle commuters. Reduced healthcare costs within the general population ( $€ 54$ million) are offset by additional costs of $€ 14$ million among additional bicycle commuters, giving a net freed opportunity cost of $€ 40$ million within the healthcare budget over the 50-year life length of the investment.

\section{Injuries}

In their health economic assessment of cycling promotion in Florence, Italy, Taddei et $\mathrm{al}^{17}$ predicted decreased traffic accidents. Woodcock $e t a l^{39}$ modelled the health impacts of active transport visions in England and Wales and also predicted a fall in road traffic and accidents under scenarios of increased walking and cycling. However, using the same general scenario for increased bicycling in Stockholm County, Nilsson $e t a l^{27}$ estimated health loss through increased DALYs due to increased numbers and types of traffic accidents, being the first major study to highlight the negative impacts of increased injuries and fatalities resulting from the shift from car to bicycle. A strength of the Nilsson study, the results of which are incorporated into our analysis of the health impacts and costs of traffic injuries, is the use of nationally representative hospital and police register data on injuries occurred.

Head and spinal injuries costs were included in an analysis of the effects of increased active travel in urban England and Wales on the National Health Service. ${ }^{16}$ However, these estimates were four times higher than the estimates used here. The current work is based on a study by Scholten $e t a l^{34}$ which assumed traumatic brain injuries occurring in about $9 \%$ of bicycle-related traffic accidents.

It has been claimed that $60 \%$ of the bicycle accidents occur due to poor infrastructure for bicycling in Sweden ${ }^{40}$ and one of the aims of the Stockholm Bicycle Plan was to increase bicycle safety by building infrastructure for active commuters. ${ }^{28}$ Improved road infrastructure has been shown to reduce bicycle fatalities by $45 \%^{41}$ and it has been suggested that increasing the number of bicyclists can also have a 'safety in numbers' effect which reduces accident risk. ${ }^{42} \mathrm{~A}$ study done by Organisation for Economic Co-operation and Development (OECD) ${ }^{43}$ showed that Sweden had the world's safest roads with the lowest number of fatal accidents per billion-cycled kilometres compared with other European countries.

\section{Total economic benefits}

Healthcare costs

This study shows a net benefit corresponding to in total of $8.7 \%$ of the 2017 Stockholm County healthcare budget after 50 years. Grabow et $a l^{36}$ reported a $5 \%$ reduction in healthcare cost attributable to a change in air pollution exposure and increased physical activity. In a scenario of daily bicycling of $3.4 \mathrm{~km}$ among urban residents in England and Wales, Jarrett $e t a l^{16}$ reported that the costs for England National Health Service would be reduced by $0.8 \%$ as a consequence of increased physical activity.

\section{Economic assessment}

It is assumed that investment in physical infrastructure would lead to increased physical activity levels and flow-on cost reductions within the healthcare sector. These assumptions have been adopted by others undertaking similar economic evaluations in which investment in infrastructure to promote active transport is assumed to increase physical activity and reduce air pollution. For example, a study conducted in Dane County in the USA reported a cost-benefit ratio of 1.87 over a 10-year cycle attributed to a US $\$ 450$ million investment in sidewalks. ${ }^{44}$ Some researchers suggest that the saved opportunity costs could finance the investment. For example, a study of air quality-related and exercise-related health benefits resulting from reduced car travel in the Midwestern USA, Grabow et $a l,{ }^{36}$ concluded that the estimated reduction in healthcare costs could finance the infrastructure change within 1-10 years. In Italy, Taddei $e t \mathrm{al}^{17}$ estimated that healthcare costs saved due to a reduction in NCDs could cover $50 \mathrm{~km}$ of new bicycle roads within 7-10 years in Florence. According to our estimates the potential health care savings could cover the infrastructure costs of bicycle lanes in 18 years.

\section{Strengths and limitations \\ Strengths}

Many previous health economic analyses of active transport interventions have used hypothetical or proposed active travel interventions; however, the scenario in this study was constructed linking register data that included home and work address coordinates ${ }^{25}$ Gender-specific and age-specific expected bicycle speeds were used to assess individuals' capacity to commute by bicycle between home and work in $30 \mathrm{~min}$ or less. ${ }^{22}{ }^{25}$ In their systematic review of active transport interventions that include physical activity benefits, Brown et at $t^{45}$ reported a limited inclusion of health effects with few studies reporting reductions in morbidity as well as mortality. Morbidity reduction is captured in the DALY weights in this study and the impacts of mortality under this 
scenario have been estimated in a companion paper. ${ }^{26}$ Additionally, the sensitivity analysis showed that the intervention is highly cost-effective even if only one-quarter of the potential bicycle commuters were to take up bicycle commuting.

\section{Limitations}

We acknowledge the limitations in the health economic modelling. It is fair to assume that improvements in population health would still occur without the intervention or increased bicycling. However, modelling all possible behavioural changes under uncertainty and generalising these to population health outcomes in the coming 50 years would be a complex exercise beyond the scope of this study. Furthermore, it would not be meaningful to base predictions on possible future health trends for which there is a lack of reliable data. Such is the case regarding air pollution trends in Stockholm since $2010^{46}$. Cost-effectiveness studies facing these and similar limitations have been published previously. ${ }^{47}$

The health impact estimates of our economic assessment are based on the Global Burden of Disease. ${ }^{48}$ We have not included all possible health impacts. We did not, for example, account for impacts on mental health (eg, depression) and obesity that are expected to result from increased physical activity. ${ }^{4950}$ A study in the USA reported that obesity reductions resulting from active transport could save US $\$ 90.93$ million in healthcare costs. ${ }^{12}$

It is possible that health benefits and cost savings are underestimated in this study due to not fully accounting for the benefits of reduced obesity and improved wellbeing that may accrue over time and flow-on to the broader community. These effects would be considered in an economic evaluation conducted from a societal perspective, which is beyond the scope of the present analysis. There are other potential savings which were not included. For example, it has been shown that people value the time bicycling to work more than the time spent in motorised transport. ${ }^{51}$ If a societal perspective had been applied, cost-effectiveness may have been higher.

Except for the effect of the mode shift towards increased bicycling, no other changes in air pollution concentrations were assumed. In terms of air pollution effects, the US Environmental Protection Agency applies segmented lag times for mortality estimates. ${ }^{52}$ However, due to the lack of studies on lag times for air pollution effects on morbidity, it was assumed that effects occurred in the same year as exposure.

In using secondary data to estimate long-term costs for chronic NCDs, there was a lack of evidence for cancer and asthma patients. Estimates are, therefore, based on the best approximations from scientific evidence published in the peer-reviewed literature. Although it is common practice for economic evaluations to draw on evidence from previous studies, comparing evidence from studies with different methodological approaches in different settings is not without its shortcomings. ${ }^{53}$ Studies from other high-income countries were used so that the results could be reasonably generalised to Sweden.

\section{CONCLUSIONS}

From a healthcare perspective investing in urban infrastructure to increase bicycling in Stockholm is cost-effective in relation to the Swedish threshold value of $€ 53$ 000 per DALY averted. This evaluation makes the best use of available data and calculates estimates based on a previously developed realistic scenario. More work of this type is needed to build an evidence base for decision-makers responsible for investing funds in public infrastructure.

Acknowledgements We thank study leaders and co-authors in the transport scenario study, in particular, Peter Schantz, Christer Johansson, Wasif Raza and Magnus Strömgren. We are grateful to the reviewers who have challenged us with constructive comments and excellent scientific feedback.

Contributors HKK planned the health economic study and undertook the data collection and economic analysis with input from LL. HKK wrote the first draft. JSW reviewed the overall content, provided input, and revised and re-drafted the paper in conjunction with HKK. BF advised on the planning and conduct of the study and was responsible for the overall transport scenario project of which this work was part. JS provided health impact estimates and critical input into the planning and conduct of the study, assisted with the statistical analyses and helped to revise the drafts. All the authors read and approved the final version of the manuscript.

Funding This work was funded by the Swedish Research Council for Health, Working Life and Welfare (grant number 2012-1296). BF received a grant (20121296) from FORTE (Forskningsrådet för hälsa, arbetsliv och välfärd) for the transport scenario study.

Competing interests None declared.

Patient consent for publication Not required.

Provenance and peer review Not commissioned; externally peer reviewed.

Data availability statement All data relevant to the study are included in the article or uploaded as supplementary information.

Open access This is an open access article distributed in accordance with the Creative Commons Attribution 4.0 Unported (CC BY 4.0) license, which permits others to copy, redistribute, remix, transform and build upon this work for any purpose, provided the original work is properly cited, a link to the licence is given, and indication of whether changes were made. See: https://creativecommons.org/ licenses/by/4.0/.

\section{REFERENCES}

1. World Health Organization. 2008-2013 action plan for the global strategy for the prevention andControl of noncommunicable diseases. Genève; 2008.

2. Cecchini M, Sassi F, Lauer JA, et al. Tackling of unhealthy diets, physical inactivity, and obesity: health effects and cost-effectiveness. The Lancet 2010;376:1775-84.

3. World Health Organization. Global recommendations on physical activity for health. Genève, 2010: 60.

4. Lee I-M, Shiroma EJ, Lobelo F, et al. Effect of physical inactivity on major non-communicable diseases worldwide: an analysis of burden of disease and life expectancy. The Lancet 2012;380:219-29.

5. World Health Organization, OECD, European Observatory. Promoting health, preventing disease. In: Davis McDaid FS, Merkur S, eds. The economic case. New York, 2015: 370.

6. World Health Organization. Physical activity fact sheet; 2016.

7. Cecchini M, Bull F. Promoting physical activity. In: David McDaid FS, Merkur S, eds. Promoting health, preventing disease the economic case. New York: McGraw Hill Education, 2015: 101-34.

8. World Health Organization. Urbanization and health. Bull World Health Organ 2010;88:245-6.

9. United Nations. Sustainable development goals; 2015.

10. IPCC. Climate change 2007 - Mitigation of climate change, 2007. 
11. World Health Organization Regional Office for Europe,, OECD. Economic cost of the health impact of air pollution in Europe: clean air, health and wealth. Copenhagen, 2015: 66.

12. Pucher J, Buehler R, Bassett DR, et al. Walking and cycling to health: a comparative analysis of City, state, and international data. Am J Public Health 2010;100:1986-92.

13. Fraser SDS, Lock K. Cycling for transport and public health: a systematic review of the effect of the environment on cycling. Eur $J$ Public Health 2011;21:738-43.

14. Cobiac LJ, Vos T, Barendregt JJ. Cost-Effectiveness of interventions to promote physical activity: a modelling study. PLOS Med 2009;6:e1000110.

15. Mulley C, Tyson R, McCue P, et al. Valuing active travel: including the health benefits of sustainable transport in transportation appraisal frameworks. Research in Transportation Business \& Management 2013;7:27-34.

16. Jarrett J, Woodcock J, Griffiths UK, et al. Effect of increasing active travel in urban England and Wales on costs to the National health service. The Lancet 2012;379:2198-205.

17. Taddei C, Gnesotto R, Forni S, et al. Cycling promotion and noncommunicable disease prevention: health impact assessment and economic evaluation of cycling to work or school in Florence. PLOS One 2015;10:e0125491.

18. Beale SJ, Bending MW, Trueman P, et al. Should we invest in environmental interventions to encourage physical activity in England? an economic appraisal. Eur J Public Health 2012;22:869-73.

19. Hanson S, Jones A. Missed opportunities in the evaluation of public health interventions: a case study of physical activity programmes. BMC Public Health 2017;17:674.

20. Weatherly H, Drummond M, Claxton K, et al. Methods for assessing the cost-effectiveness of public health interventions: key challenges and recommendations. Health Policy 2009;93:85-92.

21. OECD/EU. Health at a Glance: Europe 2016 - State of Health in the EU Cycle. Paris, 2016: 204.

22. Strömgren M, P S, Nilsson Sommar J, et al. Modelling a commuter modal shift from CAR trips to cycling: scenario construction and outcomes for Stockholm County, Sweden, 2019.

23. Stjenström $\mathrm{O}$. The Astrid data base and population geography (only in Swedish "Databasen ASTRID och befolkningsgeografi exemplen integration och barnfamiljenas geografi" Geografiska Notised;60No.2.

24. Jonsson D, Berglund S, Almström P, et al. The usefulness of transport models in Swedish planning practice. Transp Rev 2011;31:251-65.

25. Nilsson Sommar J, Schantz P, Strömgren M, et al. The potential for reduced mortality by increased cycle commuting - a health impact assessment using register data on home and work addresses in Stockholm, Sweden, 2019.

26. Nilsson Sommar J, Johansson C, Lövenheim B, et al. Overall health impacts of a potential increase in active commuting in Stockholm, Sweden, 2019.

27. Nilsson $\mathrm{P}$, Stigson $\mathrm{H}$, Ohlin $\mathrm{M}$, et al. Modelling the effect on injuries and fatalities when changing mode of transport from CAR to bicycle. Accid Anal Prev 2017;100:30-6.

28. En El AV Framkomlighetsstrategin: Cyckelplan, Stad S, 2016.

29. Livslängs och Trafikanalys. Trafikverket, 2002: 6.

30. Stockholm Läns Lansting Hälsa- och sjukvårdsnämden. Slutlig budget 2017 HSN: Förändringsarbete I fokus när vården I länet växer; 2017.

31. Kahlmeier SCNDHet al. Health economic assessment tools (heat) for walking and cycling: methodology and user guide. Copenhagen: WHO Regional Office Europe, 2011.

32. Umpierre D, Ribeiro PAB, Kramer CK, et al. Physical activity advice only or structured exercise training and association with $\mathrm{HbA} 1 \mathrm{c}$ levels in type 2 diabetes: a systematic review and meta-analysis. JAMA 2011;305:1790-9.

33. Husereau D, Drummond M, Petrou S, et al. Consolidated Health Economic Evaluation Reporting Standards (CHEERS)--explanation and elaboration: a report of the ISPOR Health Economic Evaluation Publication Guidelines Good Reporting Practices Task Force. Value Health 2013;16:231-50.

34. Scholten AC, Polinder S, Panneman MJM, et al. Incidence and costs of bicycle-related traumatic brain injuries in the Netherlands. Accid Anal Prev 2015;81:51-60.

35. Johansson C, Lövenheim B, Schantz $\mathrm{P}$, et al. Impacts on air pollution and health by changing commuting from CAR to bicycle. Sci Total Environ 2017;584-585:55-63.
36. Grabow ML, Spak SN, Holloway T, et al. Air quality and exerciserelated health benefits from reduced CAR travel in the midwestern United States. Environ Health Perspect 2012;120:68-76.

37. Woodcock J, Franco OH, Orsini N, et al. Non-vigorous physical activity and all-cause mortality: systematic review and meta-analysis of cohort studies. Int J Epidemiol 2011;40:121-38.

38. Lindsay G, Macmillan A, Woodward A. Moving urban trips from cars to bicycles: impact on health and emissions. Aust N Z J Public Health 2011;35:54-60.

39. Woodcock J, Givoni M, Morgan AS. Health impact modelling of active travel visions for England and Wales using an integrated transport and health impact modelling tool (ITHIM). PLoS One 2013;8:e51462.

40. Niska AG, Nyberg S, Eriksson, J J. Cyklisters singelolyckor - Analys av olycks- och skadedata samt djupintervjuer (sIngle bicycle accidents analysis of hospital injury data and interviews). VTI, Linköping, Sweden, 2013.

41. Schepers PM, Wegman Rob;, Fred; Heinen E. Road safety and bicycle usage impacts of unbundling vehicular and cycle traffic in Dutch urban networks. European Journal of Transport and Infrastructure Research 2013;13:221-38

42. Jacobsen PL. Safety in numbers: more walkers and bicyclists, safer walking and bicycling. Inj Prev 2015;21:271-5.

43. OECD/EU. Road safety annual report 2011. Paris: OECD International Transport Forum, 2012.

44. Guo JY, Gandavarapu S. An economic evaluation of healthpromotive built environment changes. Prev Med 2010;50 Suppl 1(Suppl 1):S44-S49.

45. Brown V, Diomedi BZ, Moodie M, et al. A systematic review of economic analyses of active transport interventions that include physical activity benefits. Transp Policy 2016:45:190-208.

46. Olstrup H, Forsberg B, Orru H, et al. Trends in air pollutants and health impacts in three Swedish cities over the past three decades. Atmos Chem Phys 2018;18:15705-23.

47. Lindholm L, Stenling A, Norberg M, et al. A cost-effectiveness analysis of a community based CVD program in Sweden based on a retrospective register cohort. BMC Public Health 2018;18:1-7.

48. World Health Organization. Global burden of disease 2004 update: disability weights for diseases and conditions. Genève: WHO, 2004: 9

49. Gill JMR, Malkova D. Physical activity, fitness and cardiovascular disease risk in adults: interactions with insulin resistance and obesity. Clin Sci 2006;110:409-25.

50. Warburton DER, Nicol CW, Bredin SS. Health benefits of physical activity: the evidence. Can Med Assoc J 2006;174:801-9.

51. Börjesson M, Eliasson J. The value of time and external benefits in bicycle appraisal. Transportation Research Part A: Policy and Practice 2012;46:673-83.

52. US. Environmental protection agency office of air quality planning and standards health and environmental impacts division. regulatory impact analysis for the final revisions to the National ambient air quality standards for particulate matter EPA452/R-12-005. Research Triangle Park: NC 27711, 2012: 474.

53. Briggs ACC, Sculpher M. Decision modelling for health economic evaluation. Oxford University Press, 2011.

54. Zhuo XH, Zhang P, Hoerger TJ. Lifetime direct medical costs of TreatingType 2 diabetes and diabetic complications. American Journal of PreventiveMedicine 2013;45:253-61.

55. Ghatnekar O, Persson U, Asplund K, et al. Costs for stroke in Sweden 2009 and developments since 1997. Int J Technol Assess Health Care 2014;30:203-9.

56. Yang Z, Zhang K, Lin P-J, et al. A longitudinal analysis of the lifetime cost of dementia. Health Serv Res 2012;47:1660-78.

57. Tran DT, Welsh RC, Ohinmaa A, et al. Resource use and burden of hospitalization, outpatient, physician, and drug costs in short- and long-term care after acute myocardial infarction. Can J Cardiol 2018;34:1298-306.

58. Dunlay SM, Shah ND, Shi Q, et al. Lifetime costs of medical care after heart failure diagnosis. Circ Cardiovasc Qual Outcomes 2011;4:68-75

59. Yabroff KR, Lamont EB, Mariotto A, et al. Cost of care for elderly cancer patients in the United States. J Natl Cancer Inst 2008; 100:630-41.

60. Tiwari A, Rahman K, Abejie B, et al. Longer duration of asthma is significantly associated with increased RV/TLC ratio. Respir Med 2017;124:44-8.

61. Jacob C, Bechtel B, Engel S, et al. Healthcare costs and resource utilization of asthma in Germany: a claims data analysis. Eur $J$ Health Econ 2016;17:195-201. 